Fixed Point Theory, 23(2022), No. 1, 267-278

DOI: $10.24193 /$ fpt-ro.2022.1.17

http://www.math.ubbcluj.ro/ nodeacj/sfptcj.html

\title{
ON MODIFIED $\mathcal{L}$-CONTRACTION VIA BINARY RELATION WITH AN APPLICATION
}

\author{
MD HASANUZZAMAN*, MOHAMMAD IMDAD** AND HAYEL N. SALEH*** \\ *Department of Mathematics, Aligarh Muslim University, Aligarh, India \\ E-mail: md.hasanuzzaman1@gmail.com \\ ** Department of Mathematics, Aligarh Muslim University, Aligarh, India \\ E-mail:mhimdad@gmail.com \\ *** Department of Mathematics, Taiz University, Taiz, Yemen \\ E-mail: nasrhayel@gmail.com
}

\begin{abstract}
In this paper, we introduce the idea of $\mathcal{L}_{\mathcal{R}}$-contraction by employing an amorphous binary relation on $\mathcal{L}$-contraction in a metric space. We prove an existence and corresponding uniqueness fixed point results for $\mathcal{L}_{\mathcal{R}}$-contraction employing an $S$-transitive binary relation on metric spaces without completeness and also furnish an illustrative example to demonstrate the utility of our main results. Finally, we apply our newly obtained results to show the existence of a non-negative solution of the first-order ordinary differential equation.

Key Words and Phrases: Fixed points, $\mathcal{L}_{\mathcal{R}}$-contraction, binary relations, differential equation. 2020 Mathematics Subject Classification: 47H10, 54H25.
\end{abstract}

\section{ACKNOWLEDGMENT.}

The authors are grateful to the referees for the constructive and fruitful comments towards the improvement of this paper. The first author acknowledges the financial assistance provided by CSIR-India in form of JRF \& SRF in the course of his $\mathrm{PhD}$ programme.

\section{REFERENCES}

[1] A. Alam, M. Imdad, Relation-theoretic contraction principle, J. Fixed Point Theory Appl., 17(2015), 693-702.

[2] A. Alam, M. Imdad, Relation-theoretic metrical coincidence theorems, Filomat, 31(2017), 44214439.

[3] A. Alam, M. Imdad, Nonlinear contractions in metric spaces under locally T-transitive binary relations, Fixed Point Theory, 19(2018), 31-24.

[4] H. Ben-El-Mechaiekh, The Ran-Reurings fixed point theorem without partial order: A simple proof, J. Fixed Point Theory Appl., 16(2014), 373-383.

[5] A. Branciari, A fixed point theorem of Banach-Caccioppoli type on a class of generalized metric spaces, Publ. Math., 57(2000), 31-37.

[6] S.H. Cho, Fixed point theorems for $\mathcal{L}$-contractions in generalized metric spaces, Abstr. Appl. Anal., 2018:1327691(2018), 6pp. 
[7] M. Hasanuzzaman, M. Imdad, Relation theoretic metrical fixed point results for Suzuki type $\mathcal{Z}_{\mathcal{R}}$-contraction with an application, AIMS Mathematics, 5(2020), 2071-2087.

[8] M. Hasanuzzaman, S. Sessa, M. Imdad et al., Fixed point results for a selected class of multivalued mappings under $(\theta, \mathcal{R})$-contractions with an application, Mathematics, 8(2020), 695.

[9] A. Jamshaid, A.E. Abdullah, Y.J. Cho et al., Fixed point results for generalized $\Theta$-contractions, J. Nonlinear Sci. Appl., 10(2017), 2350-2358.

[10] M. Jleli, B. Samet, A new generalization of the Banach contraction principle, J. Inequal. App., 2014:38(2014), 8pp.

[11] E. Karapinar, Gh.H. Joonaghanya, F. Khojasteh et al., Study of $\Gamma$-simulation functions, $\mathcal{Z}_{\Gamma}$-contractions and revisiting the $\mathcal{L}$-contractions, Filomat, 2020, 35(2021), 201-224.

[12] E. Karapınar, Fixed points results via simulation functions, Filomat, 30(2016), 2343-2350.

[13] F. Khojasteh, S. Shukla, S. Radenović, A new approach to the study of fixed point theory for simulation functions, Filomat, 29(2015), 1189-1194.

[14] B. Kolman, R.C. Busby, S. Ross, Discrete Mathematical Structures, PHI Pvt. Ltd., New Delhi, 2000.

[15] J.J. Nieto, R. Rodríguez-López, Contractive mapping theorems in partially ordered sets and applications to ordinary differential equations, Order, 22(2005), 223-239.

[16] S. Radenovic, F. Vetro, J. Vujaković, An alternative and easy approach to fixed point results via simulation functions, Demonstratio Math., 50(2017), 223-230.

[17] A.C.M. Ran, M.C.B. Reurings, A fixed point theorem in partially ordered sets and some applications to matrix equations, Proc. Amer. Math. Soc., 132(2004), 1435-1443.

[18] A.F. Roldán-López-de-Hierro, E. Karapınar, C. Roldán-López-de-Hierro et al., Coincidence point theorems on metric spaces via simulation functions, J. Comput. Appl. Math., 275(2015), 345-355.

[19] B. Samet, M. Turinici, Fixed point theorems on a metric space endowed with an arbitrary binary relation and applications, Commun. Math. Anal., 13(2012), 82-97.

[20] K. Sawangsup, W. Sintunavarat, On modified $Z$-contractions and an iterative scheme for solving nonlinear matrix equations, J. Fixed Point Theory Appl., 20:80(2018).

[21] M. Turinici, Fixed points for monotone iteratively local contractions, Demonstratio Math., 19(1986), 171-180.

Received: July 30, 2020; Accepted: November 4, 2020. 